\title{
Exploration of Teaching Method Optimization in Mechanical Drawing Course
}

\author{
J.H GONG, Q.L. CHEN, L. WANG \& C.R. Qu* \\ School of Mechanical, Electrical and Information Engineering, Shandong University, Weihai, Shandong, \\ China
}

*Corresponding author: quchangrong@163.com

\begin{abstract}
As is known to all of us, mechanical drawing is a professional course for students majoring in mechanical. In the teaching process, we find it effectively improve students' ability of space imagination if we adopt special teaching methods such as using a variety of teaching methods, developing teaching strategy according to teaching goal, a combination of traditional teaching mode and modern multimedia method. In that case, the teaching process is optimized and the teaching quality is improved.
\end{abstract}

KEYWORD: Teaching strategy; Traditional; Multimedia; Optimization

\section{INTRODUCTION}

For students majoring in mechanical, mechanical drawing is an important basic course need to grasp skilled. The main purpose of this course is to cultivate students' ability in reading and painting engineering drawing, use various mechanical drawings to design, analysis and express engineering problems. However, the lack of professional knowledge and production practice make the teaching process difficult to in-depth. In order to improve students' perception effect and to foster students' capability of space thinking, we take various measures which include designing teaching strategy, using a variety of teaching methods, a combination of traditional teaching mode and modern one, creating a variety of sensory participate in teaching atmosphere. In this way, we try to improve the structure of class, optimize the teaching process and improve teaching quality.

\section{START OF THE COURSE}

What to teach? How to teach? How to ensure that students learn the content the teachers teach? These are the three basic questions teachers faced in course design and revision. Setting goals is important, because it clear and definite what students can obtain and how can they apply them after class. In the teaching process, we need to arrange the content reasonably, to grasp the essential problem and to keep the key content. As an answer to the third question, we choose appropriate teaching method for every class, that is mean choosing one or several of the following activities in teaching process, that is lecturing, group discussion, independent study, simulation activity, case analysis and collaborative learning, etc.

\section{TEACHING PROCESS}

Classroom teaching is still the important means to realize teaching and learning, it is an effective way to guide students to learn and to achieve teaching goals. How to make the class lively and interesting, to motivate and arouse students' enthusiasm is worthy thinking about seriously.

\subsection{Teaching strategy}

\subsubsection{Break the whole into parts}

Because the attention of students normally only lasts ten to twenty minutes. For every class, we change the teaching pace for about every fifteen minutes to avoid monotony and to stimulate students' interest again.

\subsubsection{Effective questioning}

Teachers provide students opportunities to accept and deep understand the knowledge through the exchange of information, ideas and opinions face to face. Questioning and answering is the main points of learning process and effective teaching. Questions and the order in question should be able to attract students' attention, arouse their curiosity, emphasize teaching focus and promote active learning. At the 
same time, teachers can also learn about their understanding of the teaching content from the student's answer.

\subsubsection{Increase interaction}

Teaching is not only standing in front of the classroom, reciting the knowledge you know, but a special form of communication, in which voice, gestures, body movement, facial expression and eye contact may be the supplement of teaching content and may also affect the teaching process. Whatever the topic is in class, the manner you teach will produce enormous impaction on students' attention and learning effect. The best condition of teaching is just as a nature, impromptu dialogue between teachers and students which make students feel like an audience. If teachers just read according to the notes without communicating with students, the class will appear to be too formal and stiff, as a result, there will be distance between teachers and students. In addition, reading the notes will reduce opportunities to dialogue with students as well as lose eye contact with students.

\subsubsection{The use of body language.}

As everyone knows, a moving object is much more remarkable than a stationary object, so we can use body movements, such as walking around in the classroom occasionally, using powerful gesture with purpose, using facial expressions to convey emotion, to catch the attention of students.

\subsubsection{Full of enthusiasm}

All the students will be affected by the class activities no matter how high their learning motivation is at the beginning of the class. If teachers are full of enthusiasm and concern, most of the students will make positive response.

\subsection{A complementary advantage of traditional teaching mode and multimedia mode}

\subsubsection{The traditional teaching mode}

For a long time, the teaching of mechanical drawing course takes traditional teaching mode as principle. In teaching process, the teachers, as a leader, draw on the blackboard to make the students understand problem-solving steps. In this process, there are lots of communications between teachers and students. Using visual teaching method such as model, charts and physical objects during teaching process help students realize the relationship between physical objects and drawings, imagine the space shape corresponding to the view, and achieve the conversion between the plane and space. As a result, we cultivate the students' ability of space imagination. However, there are some disadvantages of traditional teaching mode which are shown as followed.

(1) Drawing on the blackboard waste lots of time which will reduce the teaching content in class.

(2) In the traditional teaching mode, teachers do not have the opportunity to communicate with students in good time as the number of students continually increases. Because it is difficult to maintain class order for teachers when there is a large number of students in class. As a result, the teaching effect will be poor.

(3)The wall charts and model, as a supplementary in traditional teaching mode, are out of line with the teaching content. The size of model is not suitable for large classes. What is more, there is no appropriate model for complicate structure and the type is single.

\subsubsection{The advantage of multimedia teaching mode}

With the continuous development of computer technology, the multimedia technology is widely used in teaching process. In the vivid and interesting teaching environment multimedia created using image and intuitive technology, students' learning interest is immensely stimulated. Multimedia teaching has created the conditions for the fundamental change of teaching method in mechanical drawing course. The advantages of multimedia are shown as followed.

(1) Save time, increase the amount of teaching content

The amount of teaching content is increased and the teaching efficiency is improved when we apply multimedia technology into teaching process. In the multimedia teaching mode, the teachers quickly present teaching resources in front of students, teach more knowledge and increase class content.

(2)Highlight emphasis, fade difficult points and improve teaching quality

The multimedia teaching mode is capable of making complexity simple, making difficulty easy, making abstraction vivid and making the emphasis and difficulty points stand out easily.

(3)Intuitive, be capable of improving envision ability

Under the use of multimedia technology, teachers can create a complete step by step by means of overlaying and cutting to geometry in the environment of AutoCAD and Cult3D. For the sake of mobilizing students' space imagination and enhancing their perceptual knowledge, teachers can also rotate, cut and remove the composite body.

(4)Demonstrate animation, enhance students' understanding

The mechanical parts with complex internal structures are difficult for teachers to express with words clearly and for students to imagine completely. Through the application of multimedia demonstration technology in animation function, all 
problems are easily solved. Animation demonstration has the advantage to make a complex teaching process easy and to enhance students' perceptual knowledge.

It can be concluded from teaching practice that using multimedia mode in mechanical drawing teaching is beneficial to improving students' interest in learning and teaching quality. However, there are some disadvantages of multimedia teaching mode. For one thing, if multimedia mode is not designed reasonably enough, the too much content may lead students cannot fully grasp. For the other thing, teachers' dominance in class is ignored in multimedia mode and the communication between teachers and students is reduced.

\subsubsection{Complementary advantages}

Firstly, teachers' dominant position should be established in class. Some basic and important content can be solved by writing on the blackboard. According to the reaction of the students, teachers make out how much the students have accepted, and then they adjust the teaching rhythm to the situation. We need the multimedia teaching mode as a supplement in mechanical drawing teaching. In teaching process, teachers should follow the principle of timely, appropriate and proper, fully use the advantages of multimedia teaching, which means to display solid model by the combination of multimedia technology and the three-dimensional CAD software, to simulate special problem solving process. Only in this way, students will absorb and master mechanical drawing technology effectively.

\section{CONCLUSIONS}

It could be deduced from teaching practice that when making teaching strategy according to special teaching goal, using the teaching method which is a combination of traditional mode and multimedia mode in mechanical drawing teaching process, teachers achieve the goal to improve teaching quality. Because the combination of two teaching modes complement each other's advantages which make positive effect in teaching process.

\section{ACKNOWLEDGEMENT}

This project was supported by school teaching research fund (No.1050513420006, No.A2012001 and No.105051242003).

\section{REFERENCES}

[1] Davies, B.2008. Teaching methods manual. Zhejiang University press.

[2] Guan, Q. \& Wang, MQ, 2012. Research on the advantages of teaching method: a combination of traditional mode and multimedia mode. Journey of Northeast Dianli University, 32(1):93-96.

[3] Tong,Y.B, 2005. Practice and thinking of multimedia teaching of mechanical drawing. Secondary vocational education, 22:35-40.

[4] Zuo, Z.Y. \& Li, K.S. \& Zhong, 2003. S.Y. Study on 3D Solid Teaching Method For Mechanical Drawing Course Based On 3D CAD. Research in Teaching, 26(2):145-148. 